Estudios Atacameños № $17-1999$

\title{
Toconce: \\ La transformación de un sistema agro-ganadero
}

Héctor Gonzílez C.'

\section{RESUMEN}

En este trabajo, eminentemente descriptivo, se presenta información sobre las actividades agrícolas y ganaderas en la comunidad de Toconce, ubicada en la cuenca del río Salado, que permite mostrar como durante el siglo XX pasaron de un sistema económico basado principalmente en la ganadería mayor (llamas, burros, mulas e, incluso, bovinos) y con un régimen de residencia más móvil y disperso, hacia otro orientado preferentemente al cultivo de hortalizas y alfalfa asociada a la crianza de ganado menor (especialmente ovinos) con un régimen residencial más localizado y nucleado alrededor del poblado de Toconce.

\section{ABSTRACT}

This paper, eminently descriptive, presents information of the agricultural and cattle-raising activities at the community of Toconce, located in the basin of the Salado river. This work allows to show like during the XX century they passed from an economic system, based mainly on the biggest cattle raising (llamas, donkeys, mules and, even, bovine) and with a more mobile and dispersed residence regime, toward another guided preferably to crops of vegetables and alfalfa sidad de Tarapacá. hgonzale@uta.cl (associated to breed of smaller livestock, especially ovine) with a more located and rooted residential régime around the town of Toconce.

\section{Introducción}

Este trabajo fue realizado en el marco del proyecto "Composición, estructura y funcionamiento de los ecosistemas terrestres a lo largo de un gradiente climático en el norte de Chile",2 que incluía la utilización de información antropológica destinada a caracterizar el rol del hombre actual que vive en las comunidades de origen indígena de la provincia de El Loa en la II Región de Antofagasta, como modificador de los patrones de abundancia y distribución de especies tanto nativas como exóticas.

El rescate y análisis de la información antropológica se relacionaba con la hipótesis del proyecto que postulaba que el hombre jugó un importante rol en la modificación del paisaje, ya que alteró el grado de heterogeneidad espacial, afectando de esta manera la diversidad y abundancia de especies y las sucesiones secundarias en el área. Siguiendo el postulado anterior, se plantearon cuestiones específicas según se tratara de las actividades agrícolas (cultivos) o ganaderas (pastoreo) que durante los años 1996 y 1997. En parte del trabajo de recolección de datos correspondiente a Toconec participó también el antropólogo Franco Venegas. 
desarrollan en las comunidades de origen indígena del área. En el caso de las actividades agrícolas se postuló que el avance o retroceso de la superficie de cultivo modifica la heterogeneidad espacial, determinando la existencia de parches o sectores de cultivo con distintos tiempos de abandono/uso, por lo que la sucesión vegetal secundaria se encontrará en distintos estados serales en cada uno de ellos y que esta situación repercute, a su vez, en una mayor diversidad de especies a nivel del conjunto de parches, ya que se pueden encontrar especies sucesionales tempranas, medias y tardías. En el caso de las actividades ganaderas, se planteó que el sistema de pastoreo extensivo del ganado doméstico es capaz de alterar la composición y abundancia de las distintas especies en la zona altiplánica, hipotetizándose que aquellas zonas sometidas a una fuerte presión de pastoreo estarían dominadas por especies no palatables y, en general, presentarían una baja diversidad.

Para poder verificar lo anterior, se seleccionaron sitios donde la interacción hombre-ambiente era diferencial, en términos del predominio de actividades agrícolas y/o ganaderas. Uno de los sitios tipo elegido fue la comunidad de Toconce, ubicada en el Loa Superior, en la cuenca del río Salado. Este trabajo, complementario del biológico, ${ }^{3} \mathrm{co-}$ rresponde al informe antropológico, destinado a rescatar información sobre las características de las explotaciones agrícolas, la delimitación de los sectores de cultivo en uso y abandonados, el establecimiento de cronología y causas de abandono de terrenos de cultivo, la delimitación de las áreas de pastoreo, la cuantificación de la masa animal asociada, el establecimiento de los sistemas de pastoreo, el sistema de uso de la pradera natural por tipo de animal y según variaciones climáticas estacionales (año agrícola) e históricas. Se trata de un informe constituido principalmente por información "dura" que, convencido por la opinión de colegas, se ha decidido publicar con esas características por la utilidad que pueda tener para futuras investigaciones o interesados en el área. lógica se encuentra en P. Marquet et al., 1998.

\section{La comunidad de Toconce}

La comunidad de Toconce abarca una gran área delimitada al norte por una quebrada que baja desde el abra de los cerros Echao y León y por una línea imaginaria que cruza desde el oriente del cerro Paniri hasta el cerro Ayavire; al sur por el río Hojalar (abarcando parte del interfluvio entre este río y el Salado), cruzando hasta El Tatio; por el este la frontera con Bolivia; y por el oeste el "médano" donde terminan las vegas de Turi en su porción oriental. El centro residencial es el poblado de Toconce, construído sobre la ladera sur del río homónimo, a una altura de $3.350 \mathrm{~m} . \mathrm{snm}$, a $22^{\circ}$ $12^{\prime}$ de latitud sur y a $68^{\circ} 09^{\prime}$ de longitud oeste.

Según el Censo de 1992, Toconce cuenta con 71 habitantes (34 hombres y 37 mujeres). En el poblado existen 59 viviendas, de las cuales sólo 17 son efectivamente ocupadas de manera más permanente. El resto permanece vacía durante casi todo el año y son ocupadas cuando los migrantes, radicados en Calama u otros lugares, retoman ocasionalmente para ver algún asunto, cultivar, durante las festividades de la comunidad o en las vacaciones de verano de sus hijos. De acuerdo a estimaciones oficiales, el $97,8 \%$ de su población corresponde a la categoría de pobres y el $2,2 \%$ restante al nivel medio-bajo (Fichas CAS, Municipio de Calama). La comunidad cuenta con estación médico rural y recibe atención primaria a través de una ronda médica que visita el poblado cada mes. Existe una escuela de enseñanza básica unidocente, que imparte actualmente hasta cuarto año (para terminar la enseñanza básica, los niños deben optar por el internado de Caspana o trasladarse a Calama). El pueblo cuenta con agua domiciliaria través de un arranque que se distribuye entre las distintas viviendas. Cuentan también con energía eléctrica por 4 horas diarias, producida por un generador accionado por una turbina propiedad de ESSAN. La localidad cuenta con Iglesia, una sede social, una edificación destinada a posta, escuela y un retén de Carabineros. En el lugar también existen dependencias de ESSAN.

El pueblo de Toconce se forma recién a principios del siglo XX, por lo que pertenece a la categoría de poblados que han resultado de su propia dinámica de crecimiento demográfico o expansión económica, que tienen un origen autónomo, no 
colonial (Martínez, 1985). Hasta fines del siglo XVIII, los habitantes del sector residían de manera dispersa en estancias ubicadas en sectores de pastoreo (como Inacaliri, Línzor, Arenal, etc.) o de cultivo (como Copacollo, Potrero, Patillón, etc.), entre las cuales se desplazaban para manejar sus animales y siembras (Martínez, op cit; Castro y Martínez, 1996). Este patrón de residencia dispersa y móvil continuó incluso una vez creado el poblado de Toconce, durante parte del presente siglo.

Los principales factores que provocaron la desestructuración del antiguo patrón de residencia dispersa fueron, por un lado, la migración a Calama y el despoblamiento de las estancias provocada por la atracción económica generada por la explotación del mineral de Chuquicamata, que se inicia a fines de la segunda década de este siglo, pero adquiere mayor envergadura hacia los años cincuenta; $y$, por otro, la desertificación de los sectores más altos (como las vegas de Inacaliri) por la extracción de aguas con destino mineroindustrial y de consumo urbano. El "golpe de gracia" se produce en los años sesenta, cuando la creación de la escuela local obliga a mantener los menores en edad escolar en el poblado de Toconce.

\section{Las actividades agrícolas}

Actualmente los lugareños sólo siembran en sectores ubicados en el curso o las inmediaciones del río Toconce, desde el cual se abastecen de las aguas necesarias para su regadío (Gómez, 1980). Los actuales sectores de cultivo son conocidos como Potrero, Patillón y Toconce. El más alejado de ellos (Potrero) se encuentra a $6,5 \mathrm{~km}$ del poblado siguiendo el curso del río. Antiguamente, sin embargo, concordando con un sistema residencial más disperso y en consonancia con una mayor importancia de la ganadería extensiva (llamas, ovinos e, incluso, vacunos), ocupaban también otros puntos más altos en el mismo río (como Mesada) o ciertos sectores del río Hojalar (como Copacollo y Hojalar). Estas áreas de cultivo, ubicadas en sectores de mayor altura, estaban más cercanas a sus estancias ganaderas, donde mantenían su residencia más permanente.

Patillón y Potrero también formaban parte del sistema de sectores antiguos de cultivo. En el curso del río Toconce, Potrero parece haber sido el sector agrícola más importante. De acuerdo a la memoria local, el sector de cultivos de Toconce, el más relevante en la actualidad y en torno del cual se ha nucleado la población, recién se habría habilitado a finales del siglo pasado, cuando se construyó el sistema de canales necesario para su regadío. Hacia comienzos de siglo, sólo habría tenido alrededor de 5 hás., cultivándose alfalfa y maíz $y$ algunos frutales (como ciruelos y tunas), y una población de aproximadamente 30 personas (Risopatrón, 1910 y 1918).

En el sistema actual, el sector Toconce concentra el $80,4 \%$ de los terrenos, siguiendo en importancia Patillón (con un 18,6\%) y luego Potrero (con apenas un $1,0 \%$ ). Es decir, comparado con el sistema antiguo, aparte que ya no se cultiva en otros puntos, como en el Hojalar, en el río Toconce se ha invertido la situación: Toconce, el sector menos importante, pasó a ser el principal, desplazando a Potrero, que se convierte en un sector prácticamente abandonado. Esta nueva articulación se relaciona con el nucleamiento de la población en torno al poblado de Toconce, estableciéndose una relación entre mayor ocupación y más proximidad.

\section{Antiguos sectores de cultivo}

Entre los sectores de cultivo actualmente abandonados $^{4}$ se encuentran:

\section{Mesada}

Sector de cultivo ubicado en la parte alta del río Toconce, en el punto que desde el camino que va de Toconce a Línzor se comienza a avistar el volcán Línzor, un poco más abajo de una pequeña cascada que se forma en el lugar. Los terrenos de cultivo están actualmente llenos de maleza (o "monte", según los lugareños). La mayor parte de estos terrenos eran de Trifunio Ayavire (su hijo Pablo, reside hoy en Toconce). El sector se utilizaba principalmente para sembrar quinoa y papas. La última persona que cultivó en el lugar, lo hizo hace 20 años atrás, cuando sembró quinoa.

Potrero, Patillón y Toconce, que también tuvieron un rol en el sistema agrícola antiguo, se tratan aparte. 


\section{Copacollo}

Sector de cultivo ubicado en la parte alta del río Hojalar, unos $11 \mathrm{~km}$ aguas abajo de la estancia Crucero. Los terrenos de cultivo están actualmente abandonados y cubiertos por maleza ("monte"). En Copacollo residieron varias familias de apellido Berna y Ayavire. ${ }^{5}$ Se trataba de un lugar más bajo y protegido, donde también podían mantener ganado menor (ovinos y caprinos), mientras mantenían las tropas de llamas en las estancias altiplánicas. Al igual que en Mesada, en este sector se sembraba principalmente quinoa y papa (además de trigo y maíz, pero en pequeña proporción). La última persona que cultivó en el lugar lo hizo hace 14 años, cuando sembró quinoa.

\section{Hojalar}

Pequeño sector de cultivo ubicado a $12 \mathrm{~km}$ aguas abajo de Copacollo, aproximadamente a la altura del actual pueblo de Toconce. Se trata de un sector angosto que corría por aproximadamente $1 \mathrm{~km}$, regado con las aguas de una vertiente ubicada en el lugar Se utilizaba principalmente para sembrar maíz y papa. Era ocupado por las familias Anza y Huaca, aunque también acudían otras personas. Actualmente se encuentra abandonado y cubierto con maleza.

\section{Actuales sectores de cultivo}

Los actuales sectores de cultivo, que se encuentran todos en el curso del río Toconce, son los siguientes:

\section{Potrero}

Este sector de cultivos se ubica en el curso del río Toconce, en su ribera sur, a aproximadamente 6,5 $\mathrm{km}$ aguas arriba del punto en que se emplaza el poblado de Toconce. Antiguamente fue el sector agrícola más importante del río. La actual área de cultivo, con grandes trechos vacíos de por medio, corre por alrededor de mil metros siguiendo el curso del río, en la ribera sur. Es un área que se familia Yufla (Martínez, 1985). siembra cada vez menos. Actualmente se reconocen 13 pequeños predios (con un tamaño promedio de 0,028 há), que cubren una superficie total de apenas 0,357 há (véase Tabla $\mathrm{N}^{\circ} 1$ ). Estos predios pertenecen a 9 personas, 5 de las cuales residen fuera de Toconce. Los propietarios que viven de manera permanente en Toconce controlan un $60,8 \%$ de la superficie total.

Los predios son trabajados por sólo cuatro personas, lo que entrega un promedio de 0,06 há por explotación de superficie efectivamente trabajada. Tres de ellas residen en Toconce y una se moviliza entre Calama y Toconce. Dos de estos agricultores mantienen llamas en estancias cercanas (Potrero y Línzor), además de tierras en Patillón el próximo sector aguas abajo. Un $25 \%$ la superficie cubierta por estas propiedades se encuentra sin cultivar ("en blanco", toda de propietarios que residen fuera de Toconce) y otro 5,6\% está siendo preparado para sembrar (también de un migrante). Del área efectivamente cultivada (apenas 0,347 há), un $75,3 \%$ es ocupado con maíz, un $18,2 \%$ con habas y un $6,5 \%$ con papas. Como en este lugar se siembran solamente cultivos anuales, el período de ocupación efectivo durante el año corre aproximadamente entre octubre y febrero (entre la siembra y la cosecha). Aún durante este período, no reside ninguna persona de manera permanente en el lugar. Solamente acuden por el día, en ocasión de faenas (siembra-limpieza-cosecha) o de regadío (cada 8 días habas y papas y cada 16 días el maíz).

\section{Patillón}

Este sector se ubica al costado sur del río Toconce, aproximadamente $5,1 \mathrm{~km}$ aguas arriba del punto en que se emplaza el poblado de Toconce. La actual área de cultivo, con algunos trechos vacíos de por medio, corre por alrededor de $3 \mathrm{~km}$ siguiendo el curso del río. Es un área todavía importante para los toconcinos, pues, aparte de las siembra de cultivos anuales, se articula con la oferta de forraje (alfalfa) para la ganadería menor. Actualmente se reconocen 87 pequeños predios (de un tamaño promedio de 0,075 há), que cubren una superficie total de 6,496 há (véase Tabla $\mathrm{N}^{\circ} 1$ ). Estos predios pertenecen a 38 personas (con una media por propietario de 0,171 há), 25 de las cuales residen fuera de Toconce. Los propietarios que 
viven de manera permanente en Toconce (13 personas) controlan un $48,7 \%$ de la superficie total.

Los predios son trabajados por 26 personas, lo que entrega un promedio de 0,25 há de superficie efectivamente cultivada por explotación. Sólo once de ellos viven en Toconce, mientras que el resto se moviliza entre Calama (u otros lugares) y la comunidad para atender sus cultivos). Los residentes permanentes controlan el $62,2 \%$ de la superficie que cubren las actuales propiedades que se reconocen en el sector. Prácticamente toda la superficie que cubren las propiedades del sector es cultivada. El 70,7\% de la superficie está cubierta con alfalfa. El resto se siembra con cultivos anuales: un $17,1 \%$ con maíz, un $8,2 \%$ con habas y un $4,0 \%$ con papas. Los residentes permanentes tienen cubiertos un $66,9 \%$ de sus terrenos con alfalfa, mientras que los que vienen de fuera por temporadas ocupan para lo mismo un porcentaje algo superior $(76,9 \%)$. Esto significa que los migrantes tienden a sembrar menos cultivos anuales en el sector que los residentes permanentes, prefiriendo, como se verá más adelante, concentrar este tipo de cultivos en Toconce, en los sectores aledaños al poblado.

Como en este lugar se siembra preferentemente la alfalfa, un cultivo permanente, las personas que trabajan en este sector deben acudir a regarla durante todo el año, además de atender sus cultivos anuales entre octubre y febrero (entre la siembra y la cosecha). Existe una persona que mantiene vivienda en el sector, donde permanece algunos períodos del año (lo que le facilita también controlar un rebaño de llamas que mantiene en las estancias de Potrero y Línzor). El resto, acude por el día desde Toconce para regar (cada 8 días las papas y habas, cada 16 días el maíz y la alfalfa, aunque para esta última se puede ampliar el lapso de riego). Los migrantes pueden regar ellos mismos cuando están en Toconce, pero generalmente llegan a acuerdo con algún vecino o pariente para que se encargue de regar sus pertenencias, especialmente en el período en que no se trabajan los cultivos anuales (marzo a septiembre). El sector por la mayor presencia de alfalfa es ocupado también para llevar los rebaños de ovejas y caprinos (existen corrales). Esto ocurre después de cada corte (se realizan dos en el año), en noviembre y en enero-febrero, cuando dejan entrar los anima- les a los predios para que "emparejen". El período de estadía es corto (entre un par de días a medio mes, dependiendo de la extensión de terreno que controle la persona). Sin embargo, los cuidadores del ganado siguen residiendo en Toconce y sólo viajan por el día, para soltar los animales en la mañana, vigilarlos, guardarlos en la tarde y luego volver.

\section{Toconce}

Este sector se ubica en las inmediaciones del poblado Toconce, a ambos costados y bajo el mismo. Es el área principal de cultivo en términos de superficie. Sin embargo, para su regadío depende del agua que entrega ESSAN a la comunidad, que se calcula en sólo 15 1/seg (CONSECOL, 1988; Fundación Chile, 1993). Actualmente se reconocen 215 pequeños predios (de un tamaño promedio de 0,13 há), que cubren una superficie total de 28,008 há (véase Tabla $N^{\circ} 1$ ). Estos predios pertenecen a 76 personas (con media por propietario de 0,369 há), 57 de las cuales residen fuera de Toconce. Los propietarios que viven de manera permanente en Toconce (19) controlan sólo un $33,2 \%$ de la superficie total.

Los predios son explotados por 35 personas, 1o que entrega un promedio de 0,82 há por explotación de superficie efectivamente cultivada (incluida la tierra en preparación). Sólo 14 de ellos viven en Toconce, mientras que el resto se moviliza entre Calama (u otros lugares) y la comunidad para atender sus cultivos. Los residentes permanentes controlan el 49,7\% de la superficie cultivada existente en las actuales propiedades que se reconocen en el sector. Un 7,7\% de la superficie no es cultivada ("en blanco") y otro 3,0\% está siendo preparado para sembrar. El 92,3\% de la superficie en blanco y toda la que se encuentra en preparación son de propiedad de personas que se encuentran fuera de la localidad. De la superficie efectivamente trabajada ( 25,028 há), un $45,6 \%$ corresponde a cultivos permanentes (alfalfa) y el $54,4 \%$ restante a cultivos anuales (un 22,7\% con habas; un $21,4 \%$ con maíz; un $8,8 \%$ con papas; un $1,3 \%$ con ajos; y un $0,2 \%$ con otras hortalizas). Estos últimos representan un $59,3 \%$ de las tierras cultivadas por personas de la comunidad que se encuentran fuera y acuden a trabajarlas; en tanto que para los residentes, los mismos representan un por- 
centaje un poco menor $(51,4 \%)$. Esto significa que, a diferencia de lo que ocurría en el sector Patillón, en Toconce los migrantes se concentran en mayor medida en la siembra de cultivos anuales.

Como este sector se ubica aledaño al poblado, su cultivo no implica la necesidad de traslado. Los residentes deben regar la alfalfa durante todo el año, además de atender sus cultivos anuales entre octubre y febrero (entre la siembra y la cosecha). Los migrantes pueden regar ellos mismos cuando están en Toconce, pero generalmente llegan a acuerdo con algún vecino o pariente para que les riegue (marzo a septiembre) y se preocupan de establecer una presencia más prolongada en el período en que se trabajan los cultivos anuales (entre octubre y febrero). Este sector, por la presencia de alfalfa (aunque tiene una menor importancia relativa respecto de los cultivos anuales en el mismo sector, en términos absolutos es donde se ubica la mayor cantidad de hectareaje del total controlado por la comunidad en todos sus sectores de cultivo), está integrado también a la crianza del ganado menor. Se trata del sitio donde este tipo de animal permanece la mayor parte del año, alimentándolos con alfalfa verde o en heno, tirándolos a los predios después de su corte (se realizan dos anuales, en noviembre y en enero-febrero) o aprovechando la escasa oferta de forraje natural existente en las inmediaciones.

Antiguamente, cuando la ganadería extensiva de animales mayores (llamas, burros, mulares e, incluso, vacunos) tenía mayor importancia, la agricultura se desarrollaba en sectores más altos, próximos a las estancias de pastoreo, y se articulaba dentro de un patrón residencial disperso. La producción agrícola se destinaba prácticamente al autoconsumo y se centraba en los dos tipos de cultivos más importantes para los ganaderos de altura, la quinoa y la papa, a los que se agregaba el maíz y otras hortalizas y verduras (para el "gasto" de la casa) cultivados en áreas más bajas.

\section{El sistema de producción agrícola}

Actualmente, cuando el patrón residencial está nucleado en torno al pueblo de Toconce, loss sectores de cultivo se ubican en áreas más bajas, accesibles a pocas horas o alrededor del mismo poblado (Gómez, 1980). De los cultivos antiguos, la quinoa ya no se siembra, la papa tiene una incidencia relativa menor, pero se conserva el maíz, por ser los sectores bajos más propicios para su siembra. Ahora el cultivo más importante es la alfalfa, que se ha integrado a la crianza de ganado menor (ovinos y caprinos), y se han introducido además otros cultivos, como habas, zanahoria, ajo, cebolla, etc. Los cultivos anuales que ocupan mayor superficie (maíz, haba, papa, ajo) se destinan al mercado.

La alfalfa, un cultivo de tipo permanente, ocupa un $50,4 \%$ de la superficie total cultivada en la comunidad. Le siguen en importancia los cultivos anuales: el maíz (con un 20,9\%), las habas $(19,7 \%)$, las papas $(7,8 \%)$, el ajo $(1,0 \%)$ y otros de menor relevancia (de huerta, para consumo casero diario, con un $0,2 \%$ ). La alfalfa se destina a la alimentación de ovinos y caprinos (además de otros animales como burros o conejos) y, aparte del riego y los dos cortes anuales que le practican, no requiere de mayor inversión en fuerza de trabajo.

Los cultivos anuales, en cambio, requieren de una frecuencia de riego más corta (con excepción del maíz, que puede soportar un lapso de riego similar al de la alfalfa) y mayor inversión en fuerza de trabajo. Debido a las condiciones climáticas del área, sólo son posibles en el período más benigno, que en la zona corresponde al que corre entre octubre y febrero. Esta situación permite que grupos familiares que residen en otros lugares (la mayoría en Calama), puedan seguir todavía cultivando en la localidad, como una manera de incorporar ingresos complementarios (vía consumo o ventas de productos agrícolas) a los que obtienen en sus ocupaciones urbanas.

Los lugareños consideran que las siembras de los cultivos anuales son seguras desde octubre en adelante, ya que antes son más frecuentes las heladas que queman las plantas. Las papas se siembran a comienzos de octubre y se cosechan en enero, se riegan cada ocho días y se venden a $\$ 150 \mathrm{el} \mathrm{kg}$. Las habas se siembran en septiembre y se cosechan entre diciembre y febrero, se riegan cada ocho días y se venden a $\$ 120 \mathrm{el} \mathrm{kg}$ (a veces obtienen $\$ 7.500$ por el saco de $50 \mathrm{~kg}$, es decir $\$ 150$ por $\mathrm{kg}$ ). El ajo (colorado) se siembra entre agosto y noviembre y se cosecha a los cuatro meses, se rie- 
Tabla $N^{\circ} 1$

Situación de la agricultura por sectores en Toconce

\begin{tabular}{|l|l|l|r|r|r|r|}
\hline \multirow{2}{*}{ Situación } & \multirow{2}{*}{ Estado } & & \multicolumn{3}{|c|}{ Sector } & \multirow{2}{*}{ Totales } \\
\cline { 5 - 7 } & & & Potrero & Patillón & & \\
\hline No cultivado & En blanco & & 0.0000 & 2.1500 & 2.2400 \\
\hline & En preparación & & 0.0000 & 0.8300 & 0.8500 \\
\hline & Subtotal & & & 0.0000 & 2.9800 & 3.0900 \\
\hline Cultivado & Permanente & Afalfa & & 4.5940 & 11.4025 & 15.9965 \\
\hline & & Subtotal & & 4.5940 & 11.4025 & 15.9965 \\
\hline & Anual & Maíz & & 1.1110 & 5.3465 & 6.6435 \\
\hline & & Haba & & 0.5330 & 5.6920 & 6.2700 \\
\hline & & Papa & & 0.2580 & 2.2160 & 2.4900 \\
\hline & & Ajo & & 0.0000 & 0.3150 & 0.3150 \\
\hline & & Otros & & 0.0000 & 0.0550 & 0.0550 \\
\hline & & Subtotal & & 1.9020 & 13.6245 & 15.7735 \\
\hline Totales & Subtotal & & & 6.4960 & 25.0270 & 31.7700 \\
\hline
\end{tabular}

Fuente: Trabajo Terreno

ga cada ocho días, se vende en trenzas (de 100 cabezas), entre $\$ 3.000$ y $\$ 4.000$ (las de primera calidad). El maíz se siembra en septiembre y se cosecha de enero en adelante, se riega cada 15 días $y$, aunque se vende en parte, se destina preferentemente al consumo del hogar (como choclo y maíz). Las zanahorias se siembran a comienzos de octubre y se cosechan de enero en adelante, se riegan cada siete días, se cultivan en menor proporción y se destinan casi enteramente al consumo. Las lechugas se pueden sembrar todo el año, pero en partes abrigadas, se riegan cada siete días, se cultivan en pequeña extensión y se destinan al consumo. Las cebollas también se pueden sembrar todo el año, se riegan cada 15 a 20 días, se cultivan poco y se destina al consumo. También se siembran otras "verduras" (como el cilantro), durante todo el año, se riegan cada siete días, ocupan una exigua superficie y se destinan al consumo diario. En general, los cultivos anuales se concentran en la parte central del sector Toconce.

En Toconce no existen prácticamente árboles frutales, aunque algunas familias mantienen tunares, que crecen en sectores pedregosos y sólo se riegan ocasionalmente. Permanecen en producción todo el año, pero la mayor abundancia se produce entre septiembre y enero, cuando aprovechan de venderlas, alcanzando precios de $\$ 400$ a $\$ 500$ el $\mathrm{kg}$.

La alfalfa, que ocupa actualmente la mayor parte de la superficie agrícola, se cultiva preferentemente en los sectores más alejados (en Patillón y en los extremos del mismo sector Toconce). Se riega cada 15 a 20 días y cuando "sobra" agua. Los lugareños realizan dos cortes en el año: en noviembre y en enero o febrero. Del corte de un potrero (de una superficie algo mayor a la de una platabanda o era de cultivo) sacan normalmente una "pargüa" (o parva, una cantidad de heno entre 6 y 7 quintales). Después del corte se echan los corderos a las eras o los potreros.

\section{Las actividades ganaderas}

Los habitantes de Toconce mantienen actualmente ganado mayor (llamas) y menor (ovino y capri- 
no). El ganado mayor se mantiene en al área que los lugareños denominan "cerro", 6 que corresponde a sectores altos con presencia de tolar y pajonal y, en algunos casos, vegas. Estos sectores son Inacaliri (en la naciente del río San Pedro), Línzor (en la naciente de los ríos Toconce y Hojalar), Arenal (en el lado oeste del cerro El León), El Mesón (en el lado oeste del cerro Toconce) y Potrero (en el lado sur del cerro Toconce). Algunas familias también mantienen sus llamas a menor distancia, en las inmediaciones del río Hojalar.

Con excepción del sector de Inacaliri, donde se mantiene una unidad doméstica (que vigila las instalaciones de la azufrera Cabana) que cuida de manera permanente una "tropa" familiar, el resto de los animales se mantiene sin cuidador. Los encargados de las "tropas" suben a verlos regularmente o, en el caso de los que pastan en El Arenal, El Mesón y Potrero (en las inmediaciones del pueblo), se vigilan cuando bajan a tomar agua al río Toconce.

El ganado menor se mantiene a la mano, en el mismo poblado de Toconce o se traslada a sectores agrícolas cercanos (como Patillón y Potrero, en la misma quebrada del río Toconce). Algunas familias, las menos, también ocupan el sector de las vegas de Turi para mantener ovinos y caprinos. Los animales menores requieren de mayor vigilancia, por lo que se mantienen cerca de la residencia de las personas. En años de lluvia pueden ser también trasladados a sectores aledaños (como el ubicado al norte del poblado, bajo el sector El Arenal), pero también acompañados de un pastor, aunque esta situación no se produce desde hace diez años. Es probable que el alto nivel de precipitaciones caídas durante el último verano active esta práctica. Hasta ahora, ovinos y caprinos (junto a los burros que poseen algunas familias y que utilizan para la recolección de leña en los cerros cercanos) se mantienen en el poblado y son alimentados con alfalfa cortada (de la propia explotación o comprada) o echándolos en los potreros

6 Para una descripción de las zonaciones que recalizan los lugareños puede verse el detallado trabajo de C. Aldunate et al., 1981. Para una comparación sobre e] mismo tema entre los aymaras del altiplano de la región de Tarapacá, véase H. Gundermann, 1984. o platabandas sembradas con alfalfa después de los cortes.

\section{La ganadería mayor: El pastoreo de llamas}

El pastoreo de llamas es de tipo extensivo, depende de la oferta de forraje natural y, con excepción de un solo rebaño, no requiere de la presencia o acompañamiento continuo de un pastor. Para mantener este tipo de ganado, los comuneros de Toconce ocupan actualmente los sectores El Arenal, El Mesón, El Potrero, Inacaliri, Línzor y Hojalar. A continuación se describe la situación por sector, considerando sus características actuales y pasadas (esto último de acuerdo a la memoria de los informantes).

\section{El Arenal}

Se trata de un área de pastoreo de altura que se ubica en el lado occidental del cerro El León, al noreste del poblado de Toconce, contiguo al sector El Mesón. Es catalogado como un sector de "cerro" por los lugareños y comprende, en una gradiente este-oeste, sectores de pajonal (paja brava), tolar (diferentes clase de plantas abarcadas con el genérico tola) y parte de un sector arenoso denominado "médano", que se extiende prácticamente hasta las vegas de Turi. Actualmente es ocupado exclusivamente por un solo grupo doméstico (encabezado por T.C., caso 5, hombre, que llega a Toconce como "yerno" de la familia Huaca), que mantiene una tropa de 28 llamas en el sector (las que se desplazan ocasionalmente también al sector vecino de El Mesón, mezclándose con las que pastorean allí). Se mantienen sin cuidador permanente. Las llamas bajan a tomar agua al río Toconce, frente al pueblo, cada 4 ó 6 días (en tiempos más cálidos bajan cada 2 ó 3 días). En ese momento, el propietario o su hija, aprovechan de contarlas. En caso de faltar alguna, suben al sector a verlas. Además, en ocasión de la visita de una hija residente en Calama (en vacaciones o julio, para la fiesta de San Santiago el santo patrón del pueblo), es decir, cuando cuentan con mayor disponibilidad de trabajadores, aprovechan de traer la tropa a un corral de Toconce (ubicado al lado de su casa), para examinarlos, luego de lo cual se echan nuevamente al cerro. Aunque hoy la unidad doméstica que lo ocupa no reside en el sector, mantiene todavía una estancia (caserío) cono- 
Tabla $N^{\circ} 2$

Situación ganadera actual en Toconce

\begin{tabular}{|c|c|c|c|c|c|c|c|c|c|}
\hline \multirow{2}{*}{$\begin{array}{c}\mathrm{N}^{\mathrm{o}} \\
\text { Caso }\end{array}$} & & \multicolumn{2}{|l|}{ Sectores } & \multicolumn{5}{|c|}{$N^{\circ}$ de animales } & \multirow{2}{*}{ Total } \\
\hline & & Pas toreo Llamas & $\begin{array}{l}\text { Pastoreo } \\
\text { Ovino/caprino }\end{array}$ & & Caprinos & Llamas & Alpacas & Burros & \\
\hline 1 & Toconce & $\begin{array}{l}\text { Mesón } \\
\text { Arenal }\end{array}$ & \begin{tabular}{|l} 
Turi \\
Toconce
\end{tabular} & & 40 & 36 & 0 & 2 & 278 \\
\hline 2 & Toconce & $\begin{array}{l}\text { Mesón } \\
\text { Arenal }\end{array}$ & Toconce & & 0 & 10 & 0 & 0 & 30 \\
\hline 3 & Toconce & Hojalar & \begin{tabular}{|l|} 
Toconce \\
Patillón
\end{tabular} & & 4 & 3 & 10 & 0 & 25 \\
\hline 4 & Toconce & Hojalar & \begin{tabular}{|l|} 
Toconce \\
Patillón
\end{tabular} & & 8 & 6 & 0 & 0 & 39 \\
\hline 5 & Toconce & $\begin{array}{l}\text { Ärenal } \\
\text { Mesón }\end{array}$ & \begin{tabular}{|l|} 
Toconce \\
Patillón
\end{tabular} & & 3 & 28 & 0 & 1 & 55 \\
\hline$\overline{6}$ & Toconce & \begin{tabular}{|l|} 
Potrero \\
Línzor \\
\end{tabular} & \begin{tabular}{|l|} 
Toconce \\
Patillión
\end{tabular} & & 25 & 60 & 0 & 3 & 208 \\
\hline $7(1)$ & Inacaliri & & & & 0 & 3 & 0 & 0 & 3 \\
\hline 8 & Cabana & \begin{tabular}{|l} 
Inacaliri \\
Cabana \\
\end{tabular} & & & 0 & 12 & 0 & 0 & 12 \\
\hline $9(2)$ & Toconce & & $\begin{array}{l}\text { Toconce } \\
\text { Patillón }\end{array}$ & & 2 & 30 & 0 & 1 & 59 \\
\hline 10 & Toconce & & \begin{tabular}{|l|} 
Toconce \\
Patillón
\end{tabular} & & $\overline{0}$ & $\overline{0}$ & 0 & 0 & $\overline{28}$ \\
\hline 11 & Toconce & & \begin{tabular}{|l} 
Toconce \\
Patillón \\
Chulque \\
Caro \\
\end{tabular} & & 0 & 0 & 0 & 0 & 18 \\
\hline 12 & Toconce & Hojalar & \begin{tabular}{|l|} 
Toconce \\
Patillón
\end{tabular} & & 0 & 18 & 0 & 1 & 25 \\
\hline 13 & Toconce & & Toconce & & 2 & 0 & 0 & 0 & 4 \\
\hline 14 & Toconce & & & & 0 & 0 & 0 & 0 & 0 \\
\hline 15 & Toconce & Hojalar & \begin{tabular}{|l|} 
Toconce \\
Patillón \\
\end{tabular} & & 0 & 20 & 0 & 0 & 35 \\
\hline 16 & Toconce & & $\begin{array}{l}\text { Toconce } \\
\text { Chulque } \\
\text { Caro } \\
\end{array}$ & & $\overline{0}$ & 0 & 0 & 0 & 15 \\
\hline 17 & \begin{tabular}{|l} 
Toconce \\
\end{tabular} & & Toconce & & 0 & 0 & 0 & 0 & 8 \\
\hline 18 & Toconce & & Toconce & & 0 & 0 & 0 & 0 & 8 \\
\hline 19 & Toconce & Hojalar & $\begin{array}{l}\text { Turi } \\
\text { Toconce } \\
\text { Patillón } \\
\end{array}$ & & 42 & 12 & 0 & 2 & 265 \\
\hline 24 & Toconce & Turi & \begin{tabular}{|l} 
Turi \\
Toconce \\
\end{tabular} & & 12 & 13 & 0 & 0 & 70 \\
\hline $25(3)$ & Calama & & & & 0 & 0 & 0 & 0 & 0 \\
\hline $26(4)$ & Lasana & & & & 0 & 0 & 0 & 0 & 0 \\
\hline $27(5)$ & Calama & & & & 0 & 0 & 0 & 0 & 15 \\
\hline 28 & Calama & \begin{tabular}{|l|} 
Colana \\
Inacaliri \\
\end{tabular} & & & 0 & 42 & 0 & 0 & 42 \\
\hline Totales & & & & 761 & 138 & 293 & 10 & 10 & 1242 \\
\hline
\end{tabular}


cida con el mismo nombre que el sector (El Arenal). Antiguamente, sin embargo, este sector incluía también el "médano" que se extiende, por el oeste, hasta llegar casi a las vegas de Turi, entre la quebrada que baja del abra de El Echao y El León por el norte y la quebrada de Toconce por el sur.

El sector de "médano", ubicado a más baja altura, antes era ocupado entre abril y agosto, para aprovechar los pastos que crecían favorecidos por las lluvias estivales, y se destinaba al pastoreo del ganado menor (ovinos y caprinos). Esta situación determinaba que existiesen varias estancias (caseríos) diseminadas por el sector, las que ocupaban los habitantes del lugar cuando residían temporalmente en esta área para aprovechar el forraje natural. No obstante, para abastecerse de agua, los lugareños debían llevarla a lomo de burro desde el río Toconce. De acuerdo a la memoria actual de los informantes, es posible constatar la existencia de las siguientes estancias:

* El Arenal: unifamiliar, de P. Huaca (fallecido, suegro del actual ocupante del sector).

* Tiguno (en una pequeña vega formada por una vertiente, al este de El Rancho): unifamiliar, de N. Berna.

* Sin nombre (más arriba de Tiguno): unifamiliar, de J. Cruz.

* El Rancho: al oeste de El Arenal, un caserío mayor de tipo multifamiliar (se mencionan viviendas de O. Lovera, J. Lovera, N. Berna )

* Quebrada Amarilla: unifamiliar, del actual ocupante del sector.

* Sin nombre: unifamiliar, de F. Lovera.

* Chiñaca: unifamiliar, de E. Ayavire. Actualmente se reconoce como de $S$. Ayavire, que vive en Toconce.

* Sin nombre: unifamiliar, de A. Lovera, que vive actualmente en Toconce y ocupa El Mesón.

* Sin nombre (al sur del camino a Turi): unifamiliar, de J. Salvatierra.

* Morro: unifamiliar, de S. Ayavire, que vive en Toconce.

* Palo Parado: unifamiliar, de S. Ayavire, que vive en Toconce.

* Mal Parado: sector de pastoreo, sólo viviendas derruidas.

* Punta Negra (a la entrada de Toconce): sector de pastoreo, sólo viviendas derruidas.

\section{El Mesón}

Se trata de un área de pastoreo que se ubica en el lado occidental del cerro Toconce, al noreste del poblado homónimo, entre los sectores El Arenal (por el norte) y Potrero (al sureste). Es catalogado como un sector de "cerro" por los lugareños y comprende sectores de pajonal (paja brava) y tolar (diferentes clase de plantas abarcadas con el genérico "tola"). Actualmente es ocupado por dos unidades domésticas (padre e hija, aunque esta última reconocida por un hermanastro), encabezadas por A.L. (caso 1, hombre) y A.S. (caso 2 , hombre, esposo de la mencionada), que mantienen dos tropas en el sector, con 36 y 10 llamas respectivamente. Los animales se desplazan también hacia el sector El Arenal (bajo el cerro El León). Los animales se mantienen sin cuidador. Las llamas bajan a tomar agua cada 4 ó 5 días al río Toconce. Si se percatan que falta algún animal, suben a ver los animales al sector alto (en un desplazamiento que ocupa un día, salen en la madrugada y están de vuelta al atardecer). En un caso, la esposa es la que oficia de pastora del ganado de la familia.

Aunque las dos unidade (Hmésticas que ocupan el sector no residen en el área. reconocen como suyas dos estancias (casemu cn el área: Peña Blanca o Paradero Cuatro y El Mesón. Antiguamente este sector era ocupado también por otras familias. De acuerdo a la memoria actual de los informantes, las estancias existentes en el sector eran:

* Peña Blanca o Paradero Cuatro: multifamiliar, era ocupada por A. Lovera (actual ocupante del sector), M. Yufla (fallecido) e I. Bartolo (posteriormente por su hijo).

* El Mesón: unifamiliar, de A. Lovera (actual ocupante del sector).

* La Cueva: multifamiliar, de E. Ayavire (fallecido) y E. Bartolo (fallecida), actualmente se reconoce como de $S$. Ayavire, que vive en Toconce).

* El Enganche: unifamiliar, de I. Bartolo (fallecido).

También se menciona como ocupante del sector a $N$. Berna (que tenía estancia en Tiguno y El Rancho, pero sus animales pasteaban entre Arenal y Mesón). 


\section{El Potrero}

Se trata de un área de pastoreo que se ubica en el lado sur del cerro Toconce, al este del poblado de Toconce, entre los sectores El Mesón (por el norte) y Línzor (al este). Es catalogado como un sector de "cerro" por los lugareños y comprende sectores de pajonal (paja brava) y tolar (diferentes clase de plantas abarcadas con el genérico "tola"). Actualmente es ocupado por una sola unidad doméstica (D.B., caso 6, hombre), que mantiene una tropa de 15 llamas en el sector (la mayor parte de sus llamas las tiene en Línzor). Los animales se mantienen sin cuidador. Las llamas bajan a tomar agua al río Toconce, cada 3 ó 4 días, un poco más arriba del sector de cultivos que también se denomina El Potrero, donde aprovechan también pequeñas vegas que se forman en las márgenes del curso de agua. Para impedir que los animales pasen a las chacras de cultivo han construido un cerco de piedra. Por estar más alejado del poblado, el propietario sube regularmente a ver sus animales cada 15 ó 20 días. También, cuando reside temporalmente en el sector agrícola de Patillón o acude al sector de cultivos de Potrero, aprovecha de ver si pasa algo con sus animales cuando bajan a tomar agua al río.

Aunque el actual ocupante no reside en el sector, todavía ocupa la vivienda que mantiene en la estancia Potrero (caserío) cuando sube a ver sus animales o recolectar leña por los alrededores. Antiguamente existían también otras familias que ocupaban esta área, manteniendo viviendas en la misma estancia. Según el recuerdo de los informante, antes ocupaban este sector:

* I. Bartolo García (fallecido), casado con F. Yufla (fallecida). Potrero era su residencia principal. Sus animales ocupaban también el sector vecino de El Mesón (por lo que tenía también viviendas en las estancias Peñablanca o Paradero Cuatro y en El Enganche). También ocupaba y se desplazaba hacia otros sectores de pastoreo con sus animales, como Torre (una estancia ubicada entre Copacollo y Escalera) y Crucero (en el sector alto del río Hojalar). Sus sembríos los realizaba en Escalera (en el sector Santa Rosa del río Toconce, cerca de Patillón), en Patillón y en Toconce. Cerca de 1920 Isagio habría llegado a tener 1.200 llamas y 200 llamos.? Ocupaba Potrero y Mesón para mante- ner los llamos. En Peñas Blancas, un sector de más bajo de Mesón, tenía 200 cabras y 60 ovejas.

* Potrero es ocupado después por E. Bartolo (fallecido, hijo de I. Bartolo G.). Su residencia principal seguía siendo Potrero. Movía sus animales entre Paradero Cuatro y El Mesón (bajaban a tomar agua a la quebrada de Tordia, afluente del Toconce, donde había una aguadita). Comparada con la tropa que manejaba su padre a comienzos de siglo, en 1950 la de Enrique era bastante exigua: tenía 40 llamas, 20 cabras, 20 corderos y 10 burros. Sembraba en el El Pimiento (Potrero), en Tordia (Potrero), en Patillón y en Toconce (pero poco). A la muerte de Enrique, su segunda mujer y sus hijos (un varón y la hija de su segundo matrimonio) mantienen por los animales por algunos años y siguen residiendo en Potrero, hasta que a finales de los sesenta se trasladan a Toconce para que sus hijos vayan a la escuela. A partir de ese momento, sólo van en verano a Potrero (vacaciones escolares), hasta que finalmente dejan de acudir. Actualmente M. Bartolo (la única hija de Enrique que sigue en Toconce) vive en el poblado y ya no tiene llamas, sólo unas cuantas ovejas que mantiene en un corral en el poblado, las que alimenta con alfalfa propia o que adquiere en Turi. Tiene terrenos agrícolas en Potrero (no siembra), en Patillón (alfalfa) y en Toconce.

* Antiguamente Potrero era también ocupado por A. Anza (fallecido). A partir de los matrimonios de sus hijas, adquieren derechos los troncos familiares de sus yernos. En este caso se encuentran D. Berna, el actual ocupante del sector y los Ayavire.

\section{Inacaliri}

Lo que se conoce actualmente como Inacaliri, es un gran sector altiplánico ubicado en el área comprendida entre los cerros Paniri, Echao y El León por el oeste y la frontera boliviana por el este, que corresponde a las nacientes del río San Pedro.

Como un factor agregado a la desecación misma del área de pastoreo y su impacto en el tamaño de las tropas, los informantes consignan también que, en 1925, cuando se empezaron a colocar las tuberías de la aducción Línzor, los trabajadores instalados en el lugar les robaban ganado a los lugareños. 
Abarca sectores de vega (Colana, Inacaliri y Cabana) y de tolar y pajonal de los cerros aledaños. En el sector de Colana se mantiene actualmente una "tropa" de 42 llamas, de propiedad de dos personas de apellido Ayavire (tío y sobrina, casos 7 y 8), que residen en Calama. Los animales se mantienen sin cuidador permanente y deambulan entre las vegas de Colana y la porción norte de Inacaliri y los cerros aledaños, utilizando como abrevaderos ciertos sectores de Colana y la estancia El 31. La mujer sube cada dos o tres meses a verlos desde Calama. En el sector de InacaliriCabana se mantiene otra "tropa" de 45 llamas, correspondiente a los hermanos Berna (a cargo de uno de ellos que vive permanentemente en Cabana, como vigilante de la azufrera homónima). La mayor parte de los animales (30) pertenece a la viuda de su hermano, que vive en Toconce. Los animales se manejan prácticamente solos y deambulan entre las vegas de Inacaliri (sector sur) y Cabana y los cerros aledaños. Utilizan como abrevadero las aguas que rebalsan de la represa Inacaliri.

En el sector se reconocen todavía las siguientes estancias (de norte a sur):

* Estancia El 31: se ubica al oeste de la vega Colana y se encuentra abandonada, era ocupada antes por U. Ayavire, que todavía mantiene, junto a un tío, una tropa en el sector.

* Colana: se ubica al este de la vega homónima, es ocupada por U. Ayavire y su tío.

* Sin nombre: se ubica más abajo de El Cuarenta, actualmente desocupada, era de D. Cruz (viuda de Z. Berna), la ocupaba para llevar los corderos en invierno (en verano los mantenían en la vega Inacaliri, frente a El Cuarenta).

* El Cuarenta: conocida antes como Inacaliri, se ubica al oeste de la vega Inacaliri, entre El Echao y el Panire, era ocupada por V. Berna y ahora pertenece a D. Cruz (viuda de Z. Berna, que vive en Toconce) y a J. Berna Ayavire (vive en la azufrera Cabana), ambos mantienen una tropa en el sector. * El Inca: se ubica a $6 \mathrm{~km}$. más abajo de la junta del Inacaliri con el Cabana, se encuentra actualmente abandonada, era de U. Ayavire.

* El Encuentro: ubicada en la confluencia de los ríos Inacaliri y Cabana, se encuentra abandonada, pertenecía a J. Lovera, que reside actualmente en Calama y no mantiene animales en el sector.
* Sin nombre: ubicada frente a El León, se encuentra abandona, era ocupada también por la misma J. Lovera.

Las vegas de este sector sufrieron un agudo proceso de desertificación por la extracción de aguas de los ríos Siloli (por parte del FFCCAB, que instala una primera cañería en 1906 y una segunda a comienzos de los cincuenta) e Inacaliri (por parte de Codelco, en 1955); y la contaminación de las aguas de Cabana por la azufrera homónima. Antes el sector funcionaba como una rica área de pastoreo, donde se mantenía gran cantidad de animales. De hecho, contrastando con la cantidad existente hoy, los Berna recuerdan que hacia el año 1958 mantenían 500 llamas y 300 corderos, en el sector comprendido entre El Cuarenta y El Inca (incluído Cabana). Según el recuerdo de los informantes en todas las estancias vivían 2 ó 3 personas. La gente se trasladaban entre las estancias e iban muy poco a Toconce. Durante el período estival, en las vegas de Colana e Inacaliri se mantenían vacunos, llamas, ovinos y caprinos. En el invierno los vacunos se trasladaban a Línzor (que era más abrigado), en tanto que el resto de los animales se tiraban a los cerros cercanos (pues la vega se enfangaba), donde las lluvias de verano favorecían el crecimiento de pastos.

La vega de Colana era ocupada por G. Ayavire y C. Bautista (que venía de Santa Bárbara, más abajo de Ojo de San Pedro, abuelo de la esposa de J. Berna). Aparte de vacunos, llamas. corderos y cabras, ambos mantenían burros (para alimentarlos traían también pasto de Chiu-Chiu). Ellos no tenían llamos machos, pues ocupaban los burros para cargar llareta, un activo negocio de la época. G. Ayavire mantenía vacunos, los que trasladaba en invierno a Línzor. Actualmente la vega de Colana se reconoce como de los hermanos J. y U. Ayavire.

V. Lovera mantenía vacas, llamas y corderos. En el verano ocupaba la vega de Inacaliri. En el período invernal llevaba las vacas a Línzor (junto con C. Ayavire), en tanto que los demás animales los pastoreaba hacia el cerro El León. Inacaliri era ocupado también por P. Huaca, que mantenía vacunos, llamas, ovinos y caprinos. En verano ocupaba el sector de vega frente a la estancia El Cuarenta (donde residía). En invierno llevaba sus vacunos y llamas a Línzor y los ovinos y caprinos al 
sector El Arenal, frente a Toconce.

Más arriba de la vega Inacaliri, en una pampa que se forma en dirección a Linzor, pastaba también E. Yufla (tenía su vivienda poco más abajo de EI Encuentro, ahora se encuentra en Calama), que ocupaba también la vega que se forma frente a la azufrera Cabana. En el invierno ocupaba el cerro Silahuala (bajo el Cabana).

El uso de los sectores de cerro habría sido el siguiente:

Sector oeste:

* Cerro Paniri: pastaba V. Berna Ayavire

* Cerro Pacorane (delante de El Echao): pastaban G. Ayavire Choque y J. Lovera.

* El Echao, detrás del Pacorane, casi no se ocupaba por su lejanía

* Cerro El León: casi no tiraban animales porque era sólo pajonal, lo ocupaba V. Lovera

Sector este:

* Cerro Colana: pastaban C. Bautista y G. Ayavire.

* Cerro Ayavire: pastaba V. Berna (ocupaba para los llamos machos)

* Cerro Silahuala (bajo el Cabana): pastaba E. Yufla

\section{Línzor}

Se trata de un área que abarca desde el cerro Peineta (bajo el Toconce y frente al Línzor) hasta el cerro Plomo o Cenizal (en dirección a El Tatio). Comprende sectores de cerro (tolar y pajonal) y vega (la principal era conocida como Vega u Ojo Mayor). Corresponde al sector de nacimiento del río Toconce. Aunque existen varios grupos familiares que reconocen derechos en este sector, actualmente sólo es ocupado por D. B. (caso 6, hombre) que mantiene 45 llamas (otras 15 en Potrero). Los animales se mantienen en el cerro y bajan en el día a la vega, donde abrevan y comen. El propietario sube cada dos meses a ver sus animales. El resto del tiempo se los cuida una persona que trabaja como vigilante de una empresa contratista de Codelco.

El sector era ocupado antiguamente por varias familias (Huaca, Cruz, Yufla, Berna, Ayavire,
González). Se le recuerda como un sector abrigado que permitía mantener vacunos durante el período invernal. También se le menciona como un sector para mantener las llamas machos, que se ocupaban en el transporte de llareta.

El ejemplo de P. Huaca puede permitir comprender lo acontecido con la ocupación de este sector y de las antiguas estrategias de manejo pecuario. Él ocupaba la estancia Linzor, residiendo en Ojo Mayor, moviendo sus animales entre Línzor, Peineta y Crucero (altos del río Hojalar). Para mantener su ganado mayor (vacunos y llamas) ocupaba también Inacaliri (donde residía en la estancia El Cuarenta, por derechos que se reconocen del lado de su esposa) y Piedra Grande (en el Hojalar). Tenía aproximadamente 400 llamos (con alrededor de 35 machos aparte). Sus animales menores (ovinos y caprinos) los mantenía en verano en Inacaliri y en invierno en El Arenal (frente a Toconce).

\section{El Tatio}

Se trata de un área de pastoreo compartida con la comunidad de Caspana, que se ubica a diez horas de caminata desde Toconce. Comprende sectores de cerro (pajonal y tolar) y vega (El Tatio). Corresponde al nacimiento del río Hojalar (controlado por la comunidad de Toconce) y del Salado (que ya corresponde a Caspana). Según algunos informantes Toconce ocupaba la vega todos los años, mientras que la gente de Caspana sólo lo habría hecho ocasionalmente. Otros informantes señalan que la mitad de El Tatio corresponde a Toconce y la otra mitad a Caspana. Actualmente no es ocupada por ningún comunero de Toconce. Antiguamente, sin embargo, era utilizada de manera temporal por varias familias de Toconce, entre las que se mencionan las de A. Ayavire, C. Berna, J. Salvatierra y J. Anza.

* A. Ayavire, tenía su residencia permanente en Chiquiro (en los altos del río Hojalar), ocupaba El Tatio durante el período estival (entre noviembre y marzo). Llevaba llamas y ovinos.

* C. Berna, vivió hasta los años veinte (tenía su residencia permanente en Copacollo). Se dice que manejaba entre 500 a 800 llamas, que permanecían casi todo el año en El Tatio. También utiliza- 
ba este sector para sus ovejas ( 80 a 100) durante el período estival (octubre a abril). El machaje lo manejaba en El Tucle (un potrero cercado con piedras), ubicado al sur de Angosto, en la quebrada del Salado, al noreste del Tatio. En Copacollo tenía además otros cierres de piedra para los machos. A los machos sólo los sacaban para tomar agua y después los volvían a guardar.

\section{Hojalar}

Actualmente se reduce a un área de pastoreo que se ubica a corta distancia, a la altura del poblado de Toconce, a sólo una hora de camino, que aprovechan los lugareños que poseen pocas llamas. Se trata de sectores de cerro (tolar y pajonal) que se ubican al sur del poblado de Toconce en las inmediaciones del río Hojalar, donde bajan las llamas a abrevar. Antiguamente, sin embargo, en el curso del río Hojalar, se reconocían varios sectores de pastoreo, especialmente en su sector alto (como Crucero, Chiquiro, Copacollo y Hojalar).

\section{Crucero}

Se trata de un área de pastoreo ubicada en el sector más alto del curso del río Hojalar, poco más abajo de Agua Calientes, donde se ubica actualmente una turbina de Codelco (después de la turbina el agua se entuba y se pasa al río Toconce). En Crucero se vuelve a juntar agua. Más abajo aumenta nuevamente el caudal del Hojalar con la aparición de otras vertientes.

\section{Antiguamente Crucero era ocupado por:}

* I. Bartolo, que tenía su residencia principal en Potrero (en el cerro Toconce). Movía las llamas entre Potrero, El Mesón, Torre (una estancia ubicada entre Copacollo y Escalera) y Crucero.

* C. Ayavire, que tenía su residencia principal en Copacollo. Ocupaba Crucero para las llamas. Después baja todos sus animales a Copacollo.

* A. Ayavire, que tenía su residencia principal en Chiquiro. Movía sus animales entre Chiquiro, Crucero (estancias Putungo y Huaylla) y El Tatio.

\section{Chiquiro}

Se trata de una antigua área de pastoreo en las inmediaciones del río Hojalar, aproximadamente a $3 \mathrm{~km}$ aguas abajo de Crucero.

Antiguamente era ocupada por:

* A. Ayavire (fallecido, convivió con D. González, proveniente de Las Pirquitas, Argentina), que movía sus animales entre Chiquiro, Crucero y la vega El Tatio. Para sus cultivos ocupaba el sector Potrero en el río Toconce (sembraba en agostoseptiembre y luego venían a regar cada quince días, por el día).

* Luego fue ocupado por R. González (hija no reconocida de A. Aravire, que convivió con E. Yufla, fallecido). Aparte de Chiquiro, para pastorear sus animales, mantenía estancias en: Chiquita (más abajo de Chiquiro, en el nacimiento de una vertiente); en El Tatio, en el Cerro Plomo (sin nombre); en Putungo (Crucero); en Línzor (más abajo de la represa) y en Hojalar (en el sector de la turbina). R. González (acompañada por dos de sus hijos) ocupó Chiquiro hasta su fallecimiento, en 1990. En ese momento sólo manejaba alrededor de 15 llamas, las que sus hijas venden posteriormente.

\section{Copacollo}

Se trata de un sector de pastoreo ubicado en el río Hojalar, a $11 \mathrm{~km}$ aguas abajo de Crucero, en las inmediaciones de un antiguo sector de cultivos que lleva el mismo nombre. Se reconoce como un sector muy pedregoso, apto sólo para llamas. Era ocupado antiguamente por varias familias Berna. Copacollo era más importante como sector de cultivo (véase el apartado agrícola).

Antiguamente Copacollo habría sido ocupado por

C. Berna. Posteriormente fue ocupado por:

* C. Ayavire.

* C. Berna (sobrino del anterior C. Berna). Tenía llamas en El Tatio (junto a la tropa de Ciriaco) y 
en Copacollo. Vivía en la estancia Rica-Rica, ubicada frente a Crucero, entre el río Toconce y el Hojalar, donde tenía cabras y ovejas, pero pocos. En Copacollo sembraba quinoa, papa, trigo y maíz. Catalino ocupa un tiempo Copacollo y después se viene a Toconce. En ese momento aparta las llamas de la tropa de su tío C. Berna y se las trae a Potrero, agregándolas con las de sus hijos (una hija se había casado con un hijo de A. Anza ocupante de ese sector).

* C. Berna Lovera (hija del C. Berna del punto anterior). Mantenía llamas en el sector. Sus ovejas las manejaba entre Rica Rica, Toconce y La Pampa (un punto ubicado en El Rancho, un sector ubicado en el río Toconce, entre Patillón y Potrero, que ocupaba en años lluviosos, entre abril a agosto, dependiendo del pasto). Después los trasladaba a El Rancho (en El Arenal, al norte de Toconce). También iba a Potrero (donde estaban sus hermanos). Esta situación duró hasta 1952, cuando C. Berna se traslada a residir a Toconce, entrega los animales a vecinos para que se los cuiden (su hijo no puede hacerse cargo, pues se marcha a trabajar a Calama). El hijo vuelve en 1984 a Toconce. Actualmente mantiene un par de ovejas y un par de cabras.

\section{Hojalar}

Se trata del sector ocupado en la actualidad, que se ubica aproximadamente a $12 \mathrm{~km}$ aguas abajo de Copacollo y más o menos a la altura del poblado de Toconce.

Actualmente mantienen animales en el sector:

* M.A. (caso 12, hombre) que mantiene 18 llamas en el punto denominado La Isla (frente a Toconce, a una hora de camino). Los animales bajan a tomar agua a los puntos Chilquita y Champial en el río Hojalar. Va a ver sus animales cada dos meses.

* S.A. (caso 3, mujer) que mantiene 3 llamas, las que bajan a tomar agua al río Hojalar. Va a ver sus animales cada tres a cuatro meses.

*P.A. (caso 19, hombre) que mantiene 12 llamas, que bajan a tomar agua al río Hojalar. Va a ver sus animales cada dos meses.
* V.A. (caso 4, mujer) que mantiene 6 llamas, que bajan a tomar agua al rio Hojalar. Va a ver sus animales cada dos o tres meses.

* N.Y. (caso 15, mujer) que mantiene 20 llamas, que bajan a tomar agua al río Hojalar. Va a ver sus animales cada tres meses.

Antiguamente este sector era ocupado por B. Anza, que llegaba con sus animales (llamas) casi hasta las inmediaciones del río Salado.

En el sector existía también un paño de cultivo, que seguía un trecho angosto de más o menos 1 $\mathrm{km}$., para lo cual se aprovechaban las aguas de una vertiente (véase la sección agrícola). Más abajo ya no hay lugares de cultivo, sólo unos pequeños pedazos en el punto El Encuentro (del Toconce y el Hojalar).

\section{La ganadería menor: El pastoreo de ovinos y caprinos}

A diferencia del pastoreo de llamas, que es de tipo extensivo, depende de la oferta de forraje natural y no requiere de la presencia o acompañamiento continuo de un pastor; el manejo del ganado menor (ovinos y caprinos) requiere actualmente de una actividad pastoral más intensiva, que supone la disponibilidad de forraje cultivado (alfalfa auto producida o adquirida) e involucra la presencia de personas dedicadas a su cuidado diario. Los rebaños de ovinos y caprinos requieren de mayor vigilancia, por lo que se mantienen a la mano de sus propietarios o cuidadores, cerca de su lugar de residencia. En la actualidad estos animales se manejan en el mismo poblado de Toconce o en sectores de cultivo cercanos (como Patillón y Potrero, en la misma quebrada del río Toconce) a los que son trasladados de manera temporal. Algunas familias también ocupan Turi para mantener ovinos y caprinos.

Antiguamente, cuando existía un patrón residencial más disperso, ovinos y caprinos se mantenían también, durante el período estival, en las estancias de los sectores más altos, como se señaló en el apartado anterior, aprovechando la presencia de vegas. En invierno eran trasladados a sectores más abrigados de la misma área ũ otros ubicados a menor altura. Este último era el caso del área ale- 
daña al poblado de Toconce. Este sector de "médano" era ocupado entre abril y agosto, para aprovechar los pastos que crecían favorecidos por las lluvias estivales. Los requerimiento de cuidado del ganado menor determinó que en esta área existiesen varias estancias (caseríos) que ocupaban los habitantes del lugar cuando residían temporalmente. En la actualidad este sector sólo tiene una ocupación potencial, activable solamente con la posibilidad de existencia de lluvias.

La situación actual de la ganadería menor, por propietario, permite hacerse una idea de la masa animal involucrada y las características del manejo pastoril (véase también Tabla $\mathrm{N}^{\circ}$ 2).

* A.L. (Caso 1, hombre): maneja un rebaño de 200 ovinos y 40 caprinos. En esta tropa se incluyen también los animales de dos pariente (R.S. y E.L., casos 25 y 26) que viven en Calama y viajan ocasionalmente a Toconce. El rebaño es cuidado por la esposa de A.L. (S.C) y se mantiene la mayor parte del año en Turi, donde aprovechan la vega y la alfalfa que queda en los potreros después de los cortes (enero-febrero y junio). La tropa la traen sólo temporalmente a Toconce, para aprovechar el pasto que queda después de los cortes en terrenos de sus propiedad (enero-febrero y noviembre). Los animales son también alimentados con alfalfa en verde o en heno, que produce la unidad doméstica en sus predios de Turi y Toconce (sectores Toconce y Patillón). A.L. tiene también dos burros, que mantiene en un corral en Toconce. Los usa para ir a Patillón a buscar pasto o a los cerros de las cercanías para recolectar leña y llareta.

* A.S. (Caso, 2, hombre): maneja un rebaño de 20 ovinos. Esta tropa es cuidada la mayor parte del tiempo por su mujer (M.B.) y se mantiene de manera permanente en Toconce, siendo trasladada por algunos días al sector de Patillón. Estos animales se alimentan con alfalfa en verde o en heno y tirándolas, después de los cortes, a los potreros y eras de su propiedad.

* S.A. (Caso 3, mujer): maneja un pequeño rebaño de 8 ovinos y 4 caprinos. Los mantiene la mayor parte del tiempo en Toconce, alimentándolos con sus propias siembras de alfalfa (saca tres cortes anuales). También los traslada temporalmente a Patillón, cuando llueve o después de los cortes. S.A. posee, además, 10 alpacas (que consiguió como donación de un proyecto que funcionó en el sector), las que maneja entre Toconce y el río (en la entrada a las dependencias de Essan, en la subida al pueblo). Antes tenía muchas cabras (que movía entre Toconce y las estancias frente al pueblo, en el sector El Rancho del Arenal), la mayor parte de las cuales murieron por tomar agua contaminada.

* V.A. (Caso 4, mujer): maneja un rebaño de 25 ovinos y 8 caprinos. Los mantiene la mayor parte del tiempo en Toconce, aprovechando terrenos de su propiedad sembrados con alfalfa. También traslada estos animales temporalmente al sector Patillón.

* T.C. (Caso 5, hombre): maneja un rebaño de 23 ovinos y 3 caprinos. En esta tropa se incluyen animales de sus hijos. El rebaño lo cuida una hija que vive con T.C. y se mantiene en Toconce, utilizando "potreros" (parcelas regadas de mayor superficie) o eras (platabandas) sembradas con alfalfa, la que riegan cada quince días y a la que realizan 2 ó 3 cortes anuales (noviembre, febrero y marzo-abril). Después de los cortes echan los animales a las parcelas ("para que raspen todo"). También traslada los animales menores al sector de Patillón, donde tiene "potrero" (alfalfa), en los meses de junio-diciembre, cuando hay pasto suficiente, manteniéndolos por 10 ó 15 días, hasta que se acaba la alfalfa disponible. En estas ocasiones, un miembro de la unidad doméstica acude diariamente al este sector, para sacar los animales del corral en la mañana, recogerlos en la tarde y luego volverse.

* D.B. (Caso 6, hombre): maneja un rebaño de 120 ovinos y 25 caprinos. En esta tropa se incluyen animales de sus hijos que residen en Calama y suben ocasionalmente a Toconce. El rebaño lo maneja entre Toconce y Patillón, aprovechando la alfalfa que crece en los terrenos de su propiedad. En el último sector, donde tiene una casa habilitada, permanece más tiempo que el resto de los comuneros de Toconce (los que viaja diariamente a ver sus animales durante el período que los mantiene allí). La estadía más prolongada en Patillón permite a D.B. vigilar sus llamas, que pastan en Potrero y en Línzor. 
* D.C. (Caso 9, mujer): maneja un rebaño de 25 ovinos y 2 caprinos. Mantiene estos animales la mayor parte del tiempo en Toconce, donde los alimenta con la alfalfa que cultiva en terrenos de su propiedad. También los traslada al sector de Patillón después de los cortes. En años lluviosos, lleva también su ganado menor a El Rancho (frente al pueblo de Toconce, en el Arenal). Cuando esto último ocurre, D.C. se desempeña como pastora de los animales de otras personas.

*J.Y. (Caso 10, hombre): maneja un rebaño de 28 ovinos. Los mantiene la mayor parte del tiempo en Toconce, donde aprovecha la alfalfa cultivada en terrenos de su propiedad. Los traslada también temporalmente a Patillón después de los cortes de alfalfa en ese sector.

*P.Y. (Caso 11, hombre): maneja un rebaño de 18 ovinos. Los mantiene la mayor parte del año en Toconce, aprovechando la alfalfa que crece en sus terrenos. También traslada estos animales a Patillón (después de los cortes) y a los puntos denominados Chulque y Quebrada Caro, que son orillas del mismo río Toconce donde se forman pequeños cojines de pasto natural.

* M.A. (Caso 12, hombre): maneja un pequeño rebaño de 6 ovinos. Los mantiene casi todo el año en Toconce, aunque también los traslada a Patillón después de los cortes de alfalfa que realiza en terrenos que posee en ese sector.

*Z.B. (Caso 13, hombre): maneja apenas 2 ovinos y 2 caprinos. Los mantiene sólo en Toconce, aprovechando la alfalfa que cultiva en terrenos de su propiedad.

* N.Y. (Caso 15, mujer): maneja un rebaño de 15 ovinos. Los mantiene la mayor parte del año en Toconce, donde los alimenta con la alfalfa que cultiva en los terrenos de su propiedad. Los traslada también temporalmente al sector Patillón (después de los cortes).

*P.B. (Caso 16, mujer): maneja un rebaño de 15 ovinos. Los mantiene la mayor parte del año en Toconce, alimentándolos con alfalfa de su producción. También traslada estos animales ocasionalmente a Chulque y Quebrada Caro, que son orillas del mismo río Toconce donde se forman pe- queños cojines de pasto natural.

* S.M. (Caso 17, hombre): maneja un rebaño de 23 ovinos. En su "tropa" tiene incluidos 15 animales de propiedad de un matrimonio (E.L. y M.Y., caso 27), que residen en Calama y suben ocasionalmente a Toconce. S.M. maneja el rebaño de manera permanente en Toconce, aunque también los traslada temporalmente a Patillón (aprovecha la alfalfa que crece en los terrenos de E.L. y M.Y.

* M.B. (Caso 18 , mujer): maneja un rebaño de 8 ovinos, 5 de los cuales mantiene consigo y otros 3 los tiene entregados a otra mujer (F.A., esposa de P.A., caso 16). M.B. mantiene tos animales en su poder todo el año en Toconce, alimentándolo con alfalfa que produce en sus terrenos (Toconce y Patillón). También compra pasto en Turi, ya que su producción no le es suficiente.

* P.A. (Caso 19, hombre): maneja un rebaño de 180 ovinos y 42 caprinos. Los mantiene la mayor parte del año en Toconce, aunque también ocupa Turi y Patillón de manera temporal. Los animales los alimenta con alfalfa verde o heno de su propia producción y tirándolos a los predios que trabaja después de cada corte.

* N.Y. (Caso 24, mujer): maneja un rebaño de 45 ovinos y 12 caprinos. Los mantiene la mayor parte del año en Turi donde aprovechan la vega y la alfalfa que queda en los potreros después de los cortes (enero-febrero y junio). La "tropa" la traen sólo temporalmente a Toconce, para aprovechar el pasto que queda después de los cortes en terrenos de sus propiedad (enero-febrero y noviembre). Los animales son también alimentados con alfialfa en verde o en heno, que produce la unidad doméstica en sus predios de Turi y Toconce.

\section{Conclusiones}

Antiguamente existía un patrón residencial disperso, consonante con una mayor importancia de un tipo de ganadería extensiva practicada en los sectores más altos, donde aprovechaban la oferta de forraje natural, principalmente de vegas y humedales de altura y tolares y pajonales. Su vida transcurría en las estancias ganaderas, entre las que se desplazaban para aprovechar distintos tipos de 
pasturas y condiciones ambientales acordes con el tipo de animal (v.gr. animales rústicos o menos rústicos) o los sistemas de manejo (v.gr. separación de llamos machos). Acudían también temporalmente a sectores de cultivo ubicados también en cotas más altas y cercanos a sus estancias y a sectores de pastoreo ubicados también en pisos inferiores (vertiente oeste de los cerros León, Echao y Toconce), donde crecía forraje estacional producto de un régimen pluvial con mayor abundancia de precipitaciones.

La captación de aguas para uso minero-industrial o de consumo para las centros urbanos de la región, en el sector de las vegas de Inacaliri (nacientes del río San Pedro) y en Línzor (nacientes del río Toconce) provocan una desertificación paulatina del área y, por tanto, una disminución de la oferta forrajera del sector alto que soportaba el mayor dinamismo de la actividad económica comunal. Paralelamente, el inicio de la explotación del mineral de Chuquicamata, genera un foco de atracción migracional hacia Calama, que afecta también a la comunidad, especialmente a las generaciones jóvenes de reemplazo de los antiguos ganaderos, provocando un descenso de la población residente, lo que se manifiesta en las genealogías de los distintos grupos familiares y en la gran cantidad de individuos originarios de la comunidad que actualmente residen en esa ciudad.

Paulatinamente las estancias ganaderas de los sectores altos empiezan a ser abandonadas por la falta de pastos y residentes, la población comienza a nuclearse en tono al poblado de Toconce y desciende drásticamente la masa de animales mayores (llamas y vacunos). La aparición de los caminos y los vehículos motorizados, a su vez, hace diminuir la existencia de burros y mulares, reduciéndola a su mínima expresión. Los sectores de montaña también quedaron desprovistos de llareta, que los lugareños extrajeron para venderlas a comerciantes que abastecían Chuquicamata y Calama (combustible).

A este cuadro se agrega una gradual disminución del nivel de precipitaciones. Los lugareños recuerdan con nostalgia un régimen pluvial estival más generoso, que permitía la existencia de alternativas forrajeras estacionales aún en los pisos más bajos, frente al poblado de Toconce, donde exis- tieron muchas estancias que eran aprovechadas principalmente para el pastoreo de ovinos.

La cantidad de llamas que se mantienen actualmente en las vegas de Inacaliri y Línzor no se comparan con los centenares que existían hasta el primer tercio de este siglo, aparte de la desaparición del ganado bovino y el abandono de la utilización del área de El Tatio. En la actualidad el pastoreo extensivo del ganado mayor está reducido a las llamas y prácticamente en una mínima expresión. Con la sola excepción de un residente en Cabana, los animales vagan solos por el campo, adonde acuden de vez en cuando sus propietarios o se conforman con mirarlos cuando bajan a abrevar al río Toconce si permanecen en sectores más cercanos al poblado.

La ganadería menor (ovinos y caprinos), antes también de carácter eminentemente extensivo, aprovechando también las praderas naturales de acuerdo a la movilidad que proporcionaba el sistema de residencia dispersa, también se ha reducido. Actualmente estos animales se mantienen en el mismo poblado de Toconce, cercanos a las viviendas, y se impuesto un sistema intensivo de manejo, que descansa en el cultivo de la alfalfa, proporcionada en heno seco o verde y en el forrajeo de eras y potreros después de los cortes.

De esta manera, aunque se podría plantear que ha disminuido la presión sobre la pradera natural por la drástica disminución de la masa animal, lo cierto es que también la pradera ya no es la misma, pues se han producido procesos de desertificación por la extracción de aguas para usos no agrícolas o por la ausencia de precipitaciones.

Las actividades agrícolas, a su vez, han tendido a concentrarse en el sector aledaño al pueblo de Toconce o en sus inmediaciones, es decir, de lugares que pueden articularse fácilmente desde el poblado. Junto con las estancias, se abandonaron también los sectores de cultivo más altos, donde sembraban principalmente quinoa y papas, los que actualmente están cubiertos de maleza y sólo continúan vigentes en la memoria de los informantes. De los cultivos originales de los pueblos andinos, la quinoa ya no se cultiva y las papas se siguen cultivando pero en pequeña proporción. Sólo el maíz tiene mayor importancia, ya que se cultiva- 
ba en los sectores más bajos, donde se concentran actualmente las actividades agrícolas, pero se destina mayormente al autoconsumo.

La alfalfa, un cultivo de tipo permanente, cubre hoy la mayor parte de la superficie de cultivo, integrada a la crianza de ganado menor (ovinos y caprinos). Los cultivos andinos tradicionales han sido reemplazados por cultivos anuales introducidos y con clara orientación mercantil. Al tener algún grado de rentabilidad y concentrarse en sólo un periodo del año (octubre-febrero), permiten que los migrantes puedan seguir practicándolos, aún instalados en otros lugares.

De todas maneras, la superficie de cultivo ha disminuido, sea por el abandono de antiguos lugares de cultivo que han sido cubiertos por la maleza, sea por la ausencia de los propietarios de los predios que, instalados en otros lugares, sólo son capaces de cultivar una parte de la superficie total que les corresponde. El retroceso de la superficie de cultivo, sin duda, ha permitido el avance de la vegetación natural en sectores completos de cultivo o en secciones de los actualmente en uso.

\section{BIBLIOGRAFÍA}

ALDUNATE, C., J. ARMESTO, V. CASTRO y C. VI1981 LLAGRÁN. Estudio etnobotánico en una comunidad precordillerana de Antofagasta: Toconce, Boletín del Museo de Historia Natural 38: 183-223.

CASTRO V. y J. L. MARTÍNEZ "Poblaciones indígenas de 1996 Atacama" en Hidalgo et al 1996: 69-110.

CONSECOL Diagnóstico agrícola de la provincia 1988 de El Loa, Vol 1 y 2, Serplac II Región. Antofagasta, Chile

\section{MUNICIPIO DE CALAMA Fichas CAS $\mathrm{s} / \mathrm{f}$}

FOLLA, J.C. Anthropologie économique d'une 1989 communauté paysanne du désert d'Atacama: Socaire. Tesis de Maestría en Antropología, Universidad de Montreal, Montreal, Canadá

FUNDACIÓN CHILE Diagnóstico de] uso y evaluación de 1993 los recursos suelo, clima y agua en comunidades étnicas de la provircia de $\mathrm{El}$ Loa, Vol. 1 y 2, Codelco-Fundación Chile, Santiago, Chile

GÓMEZ, C. La comunidad campesina indígena 1980 del Loa superior, Tesis de Licenciatura en Antropología, Universidad de Chile, Santiago, Chile

GUNDERMANN, H. Ganadería aymara, ecología y forrajes: 1984 Evaluación regional de una actividad productiva andina, Chungará 12: 99124.
HIDALGO J., V. SCHIAPPACASSE, H. NIEMEYER, C. 1996 ALDUNATE C. y P. MEGE (Editores) Culturas de Chile: Etnografia. Sociedades indígenas contemporáneas y su ideología. Ed. Andrés Bello, Santiago, Chile.

INE Censo de Población y Vivienda de 19951992 (Resultados en REDATAM)

MARQUET, P.; F. BOZINOVIC, G. BRADSHAW, C. COR1998 NELIUS, H. GONZÁLEZ, J. GUTIÉRREZ, E. HAJEK, J. LAGOS, F. LOPEZ-CORTES, L. NÚÑEZ, E. ROSELLO, C. SANTORO, H SAMANIEGO, V. STANDEN, J. TORRES-MURA Y F. JAKSIC. LOS ecosistemas del desierto de Atacama y área andina adyacente en el norte de Chile, Revista Chilena de Historia Natural 71: 593-617.

MARTÍNEZ J.L. La formación del actual pueblo de 1985 Toconce. Siglo XIX, Chungará 15: 99124.

RISOPATRÒN L. La línea de frontera con la república 1910 de Bolivia. Imprenta Universo, Santiago, Chile

1918 Diario de viaje a las cordilleras de Antofagasta y Bolivia (1903-1904) (Con ligeras anotaciones), Revista Chilena de Historia y Geografia, vol. XXVII, 31: 152-184, Santiago, Chile

VALENZUELA, B. Epítome etnográfico de la cuenca de] 1969-70 río Salado. Provincia de Antofagasta. Chile", Boletín de Prehistoria 2-3: 7599, Santiago, Chile 
